\title{
Radioiodine Therapy and Graves' Ophthalmopathy
}

\author{
James C. Sisson ${ }^{1}$, Matthew J. Schipper ${ }^{1}$, Christine C. Nelson², John E. Freitas ${ }^{1}$, and Bartley R. Frueh ${ }^{2}$ \\ ${ }^{I}$ Nuclear Medicine Division, Department of Radiology, University of Michigan Health System, Ann Arbor, Michigan; and \\ ${ }^{2}$ Department of Ophthalmology and Visual Sciences, University of Michigan Health System, Ann Arbor, Michigan
}

\begin{abstract}
Appearances of and increases in Graves' ophthalmopathy (GO) have been reported after treatment of patients with hyperthyroidism with radioiodine. We sought to determine the rates of appearance or increase in manifestations of GO in American patients treated with radioiodine for hyperthyroidism. Methods: The study population, which consisted of 76 patients (range, 10.6-72 y), included 61 women and individuals of diverse ethnicity. The patients were followed for $1 \mathrm{y}$ after radioiodine treatment. The clinical activity score (CAS) included 10 items of ophthalmic change that were evaluated at 2 and 6 mo and at $1 \mathrm{y}$; appearance of a new item scored 1 point. We evaluated interactions of 6 covariates-prolonged hyperthyroidism, prolonged hypothyroidism, smoking, treatment with an antithyroid drug (ATD), and serum levels of thyroid-stimulating immunoglobulin (TSI) and of high free $\mathrm{T}_{3}\left(\mathrm{FT}_{3}\right)$-with the numbers of patients with 2 or more CAS points and with exophthalmometer readings increased by at least $2 \mathrm{~mm}$. In addition, patients completed a scored quality-of-life (QOL) questionnaire at baseline and at $1 \mathrm{y}$ to assess eye symptoms. Results: The mean CAS points for all patients at 2 mo was 0.63 and was not significantly different at $1 \mathrm{y}$. In 9 of $10 \mathrm{CAS}$ items, there were few patients affected at $1 \mathrm{y}$ and for the most part there were fewer patients affected than at baseline. However, exophthalmometer readings increased in $39 \%$ of patients by a mean of $2.6 \mathrm{~mm}$. Individual patients frequently exhibited increases and decreases in item manifestations. Exophthalmometer readings decreased by $2 \mathrm{~mm}$ or less in $13 \%$. Of the covariates, only hyperthyroidism prolonged by at least 2.5 mo was significantly associated with 2 or more CAS points at $1 \mathrm{y}$; no covariate was significantly associated with the development of increased exophthalmometer readings. Eye symptoms recorded in the QOL were insignificantly improved over the year; symptoms did not correlate with CAS points or with exophthalmometer readings. Conclusion: After radioiodine treatment, no substantial change was seen in manifestations of CAS items except for a modest increase in exophthalmometer readings in $39 \%$ of patients. Manifestations of CAS items frequently appeared and disappeared. Prolonged hyperthyroidism is best avoided. Ocular symptoms were insignificantly fewer at $1 \mathrm{y}$ after radioiodine therapy. The observed changes do not warrant prophylactic treatment of patients with steroids.
\end{abstract}

Key Words: Graves' ophthalmopathy; radioiodine therapy; clinical activity score; quality-of-life questionnaire

J Nucl Med 2008; 49:923-930

DOI: 10.2967/jnumed.107.049437

Received Nov. 29, 2007; revision accepted Feb. 4, 2008.

For correspondence or reprints contact: James C. Sisson, Nuclear Medicine Division, Department of Radiology, 1500 E. Medical Center Dr., Hospital B1 G505A, University of Michigan Health System, Ann Arbor, MI 48109-0028.

E-mail: jsisson@umich.edu

COPYRIGHT $\odot 2008$ by the Society of Nuclear Medicine, Inc.
$\mathbf{S}$ ome researchers have found a relationship between ${ }^{131} \mathrm{I}$ therapy for hyperthyroidism and Graves' ophthalmopathy (GO). In randomized, prospective studies, radioiodine treatments were followed by statistically significant increases in the ocular manifestations of Graves' disease when compared with surgical thyroidectomy and the administration of antithyroid drugs (ATDs); some of the patients receiving radioiodine required therapeutic interventions for the changes in GO (1-3). However, the possibility that ${ }^{131} \mathrm{I}$ precipitates or aggravates ophthalmopathy to serious degrees remains controversial (4-6).

To our knowledge, no investigations of the relationship between ${ }^{131}$ I and GO have been reported from the United States since 1989. In older, retrospective studies there was agreement that the development or progression of ocular manifestations was not greater in patients treated with ${ }^{131} \mathrm{I}$ than in those receiving medical and surgical therapies (710). The reported rates of increased ophthalmic manifestations after treatments of hyperthyroidism with radioiodine were $4 \%-5 \%$ in all patients $(7,8)$ and $23 \%$ in patients with preexisting ophthalmopathy $(10)$.

In 1990, a survey found that radioiodine was administered to at least $70 \%$ of patients with hyperthyroidism in the United States (11), and over the years preceding 1990, there were increasingly frequent prescriptions for ${ }^{131} \mathrm{I}$. This trend is likely to have continued. Thus, it is now difficult to find a suitable control group for comparisons of hyperthyroid treatments. We prospectively evaluated patients treated with ${ }^{131}$ I for hyperthyroidism with the goal of determining the rate of onset or progression of orbital inflammatory disease in this cohort. If adverse changes in the orbits are few or minor, therapists will be reassured of the safety of this treatment.

\section{MATERIALS AND METHODS}

\section{Patients}

From July 1, 1999, to June 30, 2005, each patient (including patients of all ages) who was referred to the Nuclear Medicine Therapy Clinic at the University of Michigan Health Systems for treatment of hyperthyroidism was considered a candidate for the study. Each patient exhibited a serum thyroid-stimulating hormone (TSH) level of less than $0.01 \mathrm{mU} / \mathrm{L}$ at the outset of disease and an elevated concentration of free $\mathrm{T}_{3}$ or free $\mathrm{T}_{4}\left(\mathrm{FT}_{3}\right.$ or $\left.\mathrm{FT}_{4}\right)$. Patients who met the following additional criteria for Graves' 
disease were accepted into the study: diffusely enlarged thyroid gland without palpable nodules and an elevated uptake of radioiodine by the gland. Thyroid-stimulating immunoglobulin (TSI) concentrations were measured in most patients, but because antibodies of this type may be absent in more than $30 \%$ of patients who otherwise fulfill criteria for Graves' disease $(2,3)$, the result was not a criterion for entry into the study. The smoking history of each patient was recorded. Patients who had received surgical therapy for GO were excluded. Out of concern for a possible increase in diplopia, 1 patient was given prednisone before radioiodine treatment; this patient was not entered into the study. One young patient received a 6 -wk course of prednisone beginning a few weeks after radioiodine therapy; she remained in the study. Two patients who received 1 wk of prednisone therapy because of concern for thyroid storm were also retained in the project.

During the period of enrollment, 611 patients were treated with radioiodine for hyperthyroidism of all types in the Nuclear Medicine Therapy Clinic; 127 were enrolled in the study. Those with nodular thyroid glands and those who could not or would not cooperate were not entered; there was no evidence that nonenrolled patients manifested eye disease because none were referred to specialists for management of this disorder. Thirtyeight of those accepted failed to complete the study. Because each was advised that treatment would be made available if eye symptoms developed, it is unlikely that patients sought therapy elsewhere for any manifestation of GO; none had shown eye changes of concern.

At the outset, both recruitment and retention of patients was low. Beginning in August 2002, each patient was offered $\$ 50$ for completing the program, and rates of entry and retention improved.

Demographic and laboratory data are shown in Table 1.

\section{Thyroid Diagnosis and Treatment}

Assays of sera for TSH (reference, 0.3-5.5 mU/L), $\mathrm{FT}_{4}$ (9.3$22.9 \mathrm{pmol} / \mathrm{L}), \mathrm{FT}_{3}(4.4-8.3 \mathrm{pmol} / \mathrm{L})$, and total $\mathrm{T}_{3}$ were performed in the University of Michigan Health System laboratories. Total $\mathrm{T}_{3}$ levels were measured in 10 patients, none of whom was taking medication that is known to alter protein binding of circulating thyroid hormones. Thus, total $\mathrm{T}_{3}$ was converted to $\mathrm{FT}_{3}$ (in pmol/L) by multiplying by 0.0312 . All thyroid function tests were performed by an automated analyzer. TSI indices of Graves' disease were determined at the Mayo Clinic Laboratories, and results were classified as negative $(\leq 1.3)$, indeterminate $(1.4-1.8)$, or positive $(>1.8)$.

Both diagnostic and therapeutic ${ }^{131} \mathrm{I}$ was ingested in a liquid form. Thyroid uptakes were determined at 20-26 h after 0.184 $0.37 \mathrm{MBq}(0.005-0.010 \mathrm{mCi})$ of ${ }^{131} \mathrm{I}$ were given. Neck radioactivity was measured by a scintillation probe.

Some patients were treated with ATDs, methimazole or propylthiouracil, before ${ }^{131}$ I treatments; in these patients, the values recorded for $\mathrm{FT}_{3}$ were those obtained before ATD treatment. The ATDs were discontinued at least $3 \mathrm{~d}$ before radioiodine administration. Most patients were treated with $\beta$-blockers, and this medication was continued until the patient appeared clinically euthyroid.

The therapeutic activity of radioiodine was prescribed as part of standard practice and without reference to whether the patient was entering the study. Thyroid volume was estimated by palpation, and normal volume was designated as $20 \mathrm{~mL}$; volumes assigned
TABLE 1

Background Information on Patients

\begin{tabular}{|c|c|c|}
\hline Category & No. & $\%$ \\
\hline \multicolumn{3}{|l|}{ Age $(y)^{*}$} \\
\hline All & 76 & 100 \\
\hline$>50$ & 25 & 32.9 \\
\hline $20-50$ & 45 & 59.2 \\
\hline$<20$ & 6 & 7.9 \\
\hline \multicolumn{3}{|l|}{ Sex } \\
\hline Female & 61 & 80.3 \\
\hline Male & 15 & 19.7 \\
\hline \multicolumn{3}{|l|}{ Ethnicity } \\
\hline Caucasian & 63 & 82.9 \\
\hline African American & 9 & 11.8 \\
\hline Asian & 1 & 1.3 \\
\hline Hispanic & 1 & 1.3 \\
\hline Not stated & 2 & 2.6 \\
\hline \multicolumn{3}{|l|}{ Smoking $^{\dagger}$} \\
\hline Yes & 8 & 10.5 \\
\hline No & 68 & 89.5 \\
\hline \multicolumn{3}{|l|}{ ATD $^{\ddagger}$} \\
\hline Yes & 19 & 25.0 \\
\hline No & 57 & 75.0 \\
\hline \multicolumn{3}{|l|}{ TSI index } \\
\hline$\leq 1.8$ & 14 & 18.4 \\
\hline$>1.8^{\S}$ & 34 & 44.7 \\
\hline All & 48 & 63.1 \\
\hline \multicolumn{3}{|l|}{$\mathrm{FT}_{3}(\mathrm{pmol} / \mathrm{L}) \|$} \\
\hline$<16.6$ & 31 & 40.8 \\
\hline$\geq 16.6$ & 28 & 36.8 \\
\hline All & 59 & 77.6 \\
\hline
\end{tabular}

*Age in years: mean, 42.9; SD, 14.8; range, 10.6-72; median, 44.

${ }^{\dagger}$ Cigarette smoking during previous year or during study.

${ }^{\ddagger}$ Methimazole or propylthiouracil. Discontinued at least $3 \mathrm{~d}$ before 131 therapy.

§Level considered positive and reflective of Graves' disease.

Upper limit of normal, $8.3 \mathrm{pmol} / \mathrm{L}$.

were then calculated as $2 \times$ normal $=40 \mathrm{~mL}$ and so on (12). The treatment goal was $7.4 \mathrm{MBq}(0.2 \mathrm{mCi})$ of radioiodine per milliter of thyroid tissue, using the estimated volume and the thyroid uptake percentage at $24 \mathrm{~h}$. This therapeutic protocol was adopted to minimize the duration of hyperthyroidism. Treatments of this magnitude were expected to be followed by hypothyroidism in 3-6 mo in most patients.

Patients were scheduled for their first reevaluation 7-8 wk after ${ }^{131} \mathrm{I}$ therapy, at which time serum $\mathrm{FT}_{4}$ and $\mathrm{TSH}$ were remeasured. To minimize any effects of hypothyroidism, patients received thyroxine at the first indication of thyroid function failure. In most patients, prior hyperthyroidism induced prolonged suppression of thyrotrope function and, consequently, also of serum TSH levels; at the earliest reevaluations, hypothyroidism was anticipated when the $\mathrm{FT}_{4}$ concentrations were near or below the bottom of the normal range. In all cases, disappearance of hyperthyroidism was confirmed when the TSH level rose above the lower limit of normal. Durations (from the time of ${ }^{131}$ I treatment) of hyperthyroidism and distinct hypothyroidism $(\mathrm{TSH}>6.0 \mathrm{mU} / \mathrm{L})$ were determined to the nearest half month from the medical records. 


\section{Evaluations of Orbital Disease}

Objective data were obtained to accord with 10 items in a clinical activity score (CAS) (Table 2), a method of evaluation introduced by Mourits et al. (13). All measurements were made by 1 of 3 ophthalmologists working with the same ophthalmic technician. Patients were evaluated at the time of radioiodine therapy and subsequently at 2-3, 6-7, and 12-14 mo (abbreviated as $1 \mathrm{y}$ ).

Items under the headings of "Redness" and "Swelling" (Table 2) were graded as present or absent throughout the year by observation. Specified pain was described as present or absent throughout the year by the patient. Mourits et al. (13) defined restricted ocular motility as a decrease of $5^{\circ}$ or more, but we found this index difficult to reproduce. Thus, extraocular muscle dysfunction was reported as diplopia elicited either in the primary field of gaze or in the peripheral fields only, as described by others (2). Visual acuity was assessed by reading lines on a Snellen chart at $6 \mathrm{~m}$.

Mourits et al. (13) described criteria to assess changes in the eyes. We noted the presence of items at baseline for reference of change where possible. However, increases by $2 \mathrm{~mm}$ or more in Hertel exophthalmometer readings could be determined only after baseline. We also recorded exophthalmometer readings decreased by $2 \mathrm{~mm}$ or more. Changes were scored for the maximum seen in either eye.
Data-based exophthalmos was established by exophthalmometer readings that were greater than 2 SDs above the reference values reported for age and sex $(14,15)$ and race $(16,17)$.

Vision was assessed only for deterioration, and no baseline reference value was established for this item. However, no diminution in vision was detected.

A general index of GO was an increase in the CAS of 2 points or more (a cutoff used by others (2)).

To obtain patients' assessment of eye disease, a quality-of-life (QOL) questionnaire was prepared for patients with possible GO (Appendix). The questionnaire was administered at the time of radioiodine therapy and again at $1 \mathrm{y}$.

\section{Associations with Covariates}

The association of CAS manifestations with 6 factors that have been reported to be, or could be considered to be, associated with GO were evaluated as covariates: smoking cigarettes (18) within the year preceding treatment; ATD administered before treatment; positive levels $(>1.8)$ of TSI (3); serum $\mathrm{T}_{3}$ levels $(\geq 16.6 \mathrm{pmol} / \mathrm{L})$ twice the upper limit of normal before treatment (1); prolonged hyperthyroidism (1), here by more than 2.5 mo after treatment; and prolonged hypothyroidism (3), here by more than 0.5 mo subsequent to treatment.

TABLE 2

Evaluation of Items in a CAS

\begin{tabular}{|c|c|c|c|c|c|c|c|c|c|c|}
\hline \multirow[b]{3}{*}{ Item $^{*}$} & \multirow{3}{*}{$\begin{array}{c}\text { No. } \\
\text { patients } \\
\text { (baseline) }\end{array}$} & \multicolumn{9}{|c|}{ No. patients affected compared with baseline } \\
\hline & & \multicolumn{3}{|c|}{$2 \mathrm{mo}$} & \multicolumn{3}{|c|}{$6 \mathrm{mo}$} & \multicolumn{3}{|c|}{$1 \mathrm{y}$} \\
\hline & & New & Disappear & $\begin{array}{c}\text { Net } \\
\text { change }\end{array}$ & New & Disappear & $\begin{array}{c}\text { Net } \\
\text { change }\end{array}$ & New & Disappear & $\begin{array}{c}\text { Net } \\
\text { change }\end{array}$ \\
\hline \multicolumn{11}{|l|}{ CAS items } \\
\hline \multicolumn{11}{|l|}{ Pain } \\
\hline Pain on/behind globe & 6 & 2 & 4 & -2 & 3 & 5 & -1 & 2 & 5 & -3 \\
\hline Pain with eye movement & 5 & 4 & 5 & -1 & 0 & 5 & -5 & 0 & 5 & -5 \\
\hline \multicolumn{11}{|l|}{ Redness } \\
\hline Eyelids & 2 & 1 & 2 & -1 & 0 & 2 & -2 & 0 & 1 & -1 \\
\hline Diffuse conjunctival & 14 & 7 & 11 & -4 & 6 & 1 & -4 & 9 & 11 & -2 \\
\hline \multicolumn{11}{|l|}{ Swelling } \\
\hline Eyelids & 13 & 4 & 8 & -4 & 5 & 7 & -2 & 5 & 9 & -4 \\
\hline Chemosis & 5 & 3 & 4 & -1 & 7 & 5 & 2 & 3 & 4 & -1 \\
\hline Caruncle & 1 & 2 & 0 & 1 & 1 & 1 & 0 & 1 & 1 & 0 \\
\hline $\begin{array}{l}\text { Proptosis (Hertel exophthalmometer }{ }^{\dagger} \text { ) } \\
\text { Impaired vision }\end{array}$ & $\neq$ & 18 & & & 16 & & & 30 & & \\
\hline Extraocular movement (diplopia) & 15 & 7 & 6 & 1 & 9 & 7 & 2 & 13 & 10 & 3 \\
\hline Visual acuity & $\epsilon^{\ddagger}$ & 0 & & & 0 & & & 0 & & \\
\hline \multirow[t]{2}{*}{ Total no. patients evaluated } & 76 & 72 & & & 69 & & & 76 & & \\
\hline & & & $2 \mathrm{mo}$ & & & $6 \mathrm{mo}$ & & & $1 \mathrm{y}$ & \\
\hline \multicolumn{11}{|l|}{ CAS points } \\
\hline Total points & & 48 & & & 47 & & & 63 & & \\
\hline Mean & & 0.63 & & & 0.62 & & & $0.83^{\S}$ & & \\
\hline SD & & 1.02 & & & 0.97 & & & 1.01 & & \\
\hline \multicolumn{11}{|l|}{ No. patients } \\
\hline Any points & & 31 & & & 30 & & & 41 & & \\
\hline$\geq 2$ points & & 10 & & & 11 & & & 15 & & \\
\hline \multicolumn{11}{|c|}{$\begin{array}{l}{ }^{\star} \text { One point for each item based on Mourits et al. (13). } \\
{ }^{\dagger} \text { Exophthalmometer readings } \geq 2 \mathrm{~mm} \text { above baseline. } \\
{ }^{\ddagger} \text { Only change from baseline can be measured. } \\
\text { §Differs from } 2 \text {-mo value; } P=0.174 \text {. }\end{array}$} \\
\hline
\end{tabular}


TABLE 3

Data-Based Exophthalmometer Readings: Right and Left Eyes*

\begin{tabular}{|c|c|c|c|c|c|c|}
\hline \multirow[b]{2}{*}{ Patient } & \multicolumn{2}{|c|}{ Baseline } & \multicolumn{2}{|c|}{$1 \mathrm{y}$} & \multicolumn{2}{|c|}{ Difference } \\
\hline & $\mathrm{R}$ & L & $\mathrm{R}$ & L & $\mathrm{R}$ & L \\
\hline \multicolumn{7}{|l|}{ All patients $(n=76)$} \\
\hline Mean & 18.1 & 18.2 & 18.8 & 18.8 & 0.8 & 0.6 \\
\hline SD & 3.0 & 2.7 & 3.2 & 3.3 & 1.9 & 1.9 \\
\hline \multicolumn{7}{|c|}{ All patients without change $(n=36)$} \\
\hline Mean $^{\dagger}$ & 18.1 & 17.9 & 18.1 & 17.9 & 0.0 & -0.1 \\
\hline SD & 2.7 & 2.4 & 2.7 & 2.5 & 0.8 & 0.7 \\
\hline \multicolumn{7}{|c|}{ Patients with $\geq 2 \mathrm{~mm}$ change $(n=30)$} \\
\hline Mean ${ }^{\dagger}$ & 17.7 & 17.9 & 20.2 & 20.3 & 2.6 & 2.5 \\
\hline $\mathrm{SD}$ & 3.2 & 2.6 & 3.1 & 2.8 & 1.1 & 1.3 \\
\hline \multicolumn{7}{|c|}{ Patients with $\leq 2 \mathrm{~mm}$ change $(n=10)$} \\
\hline Mean ${ }^{\dagger}$ & 19.7 & 19.9 & 17.8 & 17.5 & -1.9 & -2.5 \\
\hline SD & 3.3 & 3.3 & 3.6 & 6.8 & 1.7 & 0.9 \\
\hline
\end{tabular}

*Based on age, sex, and ethnicity data from previous publications (14-17).

${ }^{\dagger}$ Means at baseline differ, $P=0.123$.

\section{Statistical Analysis}

The Fisher exact test was used to test for any relation between the covariates and presence of 2 CAS points, as well as between the covariates and presence of new proptosis at $1 \mathrm{y}$. To test whether the presence of new proptosis had an effect on QOL, the Cochrane-Armitage test for trend was used. The relation between CAS and QOL was assessed using a $\chi^{2}$ test. The McNemar test was used to test whether the proportion of patients with exophthalmos changed from baseline to $1 \mathrm{y}$. Paired $t$ tests compared CAS points between 2 mo and $1 \mathrm{y}$. ANOVA evaluated possible differences among groups in exophthalmometer readings at baseline. Finally, the Wilcoxon signed rank test was used to test whether the mean QOL changed from baseline to $1 \mathrm{y}$. All tests were conducted using a 0.05 level of significance. All analyses were performed using the SAS system (SAS Institute).

This study was approved by the medical institution review boards of the University of Michigan.

\section{RESULTS}

\section{Objective Assessments: CAS and Other Criteria}

The numbers of patients manifesting changes in each item of CAS compared with baseline are recorded at 2 and $6 \mathrm{mo}$ and at $1 \mathrm{y}$ in Table 2. No diplopia developed in the primary field of gaze. At $1 \mathrm{y}$, there was a net decrease in the number of patients manifesting the first 6 items of CAS.
There was a net increase of 3 patients with the expression of diplopia. None had vision loss. Compared with baseline measurements, there were 30 patients who exhibited increases of $2 \mathrm{~mm}$ or more in exophthalmometer readings at $1 \mathrm{y}$; these changes are examined further later in the article and in Table 3. Variations in CAS items are evident.

For all CAS items, the total number of points attributed to all 76 patients increased from 48 at 2 mo to 63 at $1 \mathrm{y}$ (Table 2). This increment was related to the greater number of patients at $1 \mathrm{y}$ with exophthalmometer readings increased by $2 \mathrm{~mm}$ or more. The larger number of patients with a CAS increased by greater than or equal to 2 points is also attributed to the appearance of a new proptosis. Nevertheless, the mean CAS points for all patients was insignificantly changed, from 0.63 to 0.83 , during this interval $(P=0.174)$.

\section{Data-Based Exophthalmos and Exophthalmometer Readings}

Information from patients with data-based exophthalmos assessments are recorded in Table 4 . There were 16 patients who exhibited exophthalmos at baseline (21\% of all patients). Compared with baseline, there were 8 new patients with exophthalmos at $1 \mathrm{y}$, but in 2 patients, the increased

TABLE 4

Data-Based Exophthalmometer Assessments*

\begin{tabular}{|c|c|c|c|c|c|c|c|c|c|}
\hline \multirow[b]{2}{*}{ Baseline } & \multicolumn{3}{|c|}{$2 \mathrm{mo}$} & \multicolumn{3}{|c|}{$6 \mathrm{mo}$} & \multicolumn{3}{|c|}{$1 \mathrm{y}$} \\
\hline & New & Disappear & $\begin{array}{c}\text { Net } \\
\text { change }\end{array}$ & New & Disappear & $\begin{array}{c}\text { Net } \\
\text { change }\end{array}$ & New & Disappear & $\begin{array}{c}\text { Net } \\
\text { change }\end{array}$ \\
\hline 16 & 6 & 3 & 3 & 6 & 7 & -1 & 8 & 2 & 6 \\
\hline
\end{tabular}

*Based on age, sex, and ethnicity data from previous publications (14-17). 
prominence disappeared and the net increase was 6 patients, creating an insignificant change $(P=0.058)$.

Relative to baseline, exophthalmometer readings increased by $2 \mathrm{~mm}$ or more in either eye in 18 (24\%) and $16(21 \%)$ patients, respectively, at 2 and $6 \mathrm{mo}$ and in 30 (39\%) patients at $1 \mathrm{y}$ (Tables 3 and 4 ), but the trend between 2 mo and $1 \mathrm{y}$ was not statistically significant. Moreover, in the 30 patients with increased readings at $1 \mathrm{y}$, the changes were modest: $2.6 \pm 1.1$ and $2.5 \pm 1.3 \mathrm{~mm}$ in right and left eyes, respectively (Table 3 ); the largest increase in any eye was $5 \mathrm{~mm}$.

Ten patients exhibited a decrease of $2 \mathrm{~mm}$ or more in exophthalmometer readings in at least 1 eye; the largest decrease was $6 \mathrm{~mm}$. The changes in readings enabled the division of patients at $1 \mathrm{y}$ into 3 groups: those with increases greater than or equal to $2 \mathrm{~mm}(n=30)$, those with decreases greater than or equal to $2 \mathrm{~mm}(n=10)$, and those without a change $(n=36)$ (Table 3$)$. At baseline, exophthalmometer readings in the 3 groups did not significantly differ $(P=0.123)$. Also, compared with baseline assessments, the increased readings appeared more frequently in patients without data-based exophthalmos $(43 \%)$ than in those with it $(25 \%)$.

\section{Variations in Presence of Indices of GO}

Individual items (indices) of GO varied considerably over time. As noted earlier, there were appearances and disappearances of data-based exophthalmos over the year. Moreover, exophthalmometry readings increased in some and decreased in other patients.

Of the 15 patients with diplopia at baseline, only 5 exhibited this manifestation at $1 \mathrm{y}$. Diplopia also varied throughout the year: 13 patients had new diplopia at the end of the study; in 10 other patients, this dysfunction had disappeared (Table 2).

Fourteen of 57 patients (25\%) had increases to a score of 2 or more CAS points between 2 mo and the end of the year
(Table 2). Conversely, in 12 of 19 patients (43\%), the score of 2 or more points declined to less than 2 points over the same period.

A widened palpebral fissure was not an item in the CAS but is often seen in patients with GO. If widening of palpebral fissures is defined as increases of $2 \mathrm{~mm}$ or more in either eye (15), then this feature was present in only 5 patients at $1 \mathrm{y}$, and for all patients it decreased by $0.5 \pm 1.5$ $\mathrm{mm}$ during the periods of observation.

\section{Covariates}

The only covariate that was significantly $(P=0.035)$ associated with a CAS of greater than or equal to 2 points at 1 y was hyperthyroidism prolonged by at least 2.5 mo (Table 5). No covariate was statistically associated with an increase by $2 \mathrm{~mm}$ or more in exophthalmometry readings at $1 \mathrm{y}$.

The therapeutic activity of radioiodine has not been considered a factor in the development of GO, and a relationship was not found in our patients. At $1 \mathrm{y}$, the correlation between treatment dose and CAS points was 0.07 and not significantly different from $0(P=0.56)$.

\section{QOL}

The total number of QOL points for the 75 patients who completed the questionnaire decreased from 113 to 79 . The mean decrease in points per complaining patient, from $1.51 \pm 2.32$ to $1.05 \pm 1.579$ (Table 6), was insignificant $(P=0.673)$. The number of patients who had at least $2 \mathrm{QOL}$ points declined over the year from 27 to 22 . The correlation between a CAS of 2 or more points and a QOL score of 2 or more points at $1 \mathrm{y}$ (Table 7$)$ was also insignificant $(P=$ 0.101). In addition, the correlation between a QOL score of 2 or more points and exophthalmometer readings of $2 \mathrm{~mm}$ or more at $1 \mathrm{y}$ (Table 7$)$ was insignificant $(P=0.648)$.

TABLE 5

Associations of Covariates and CAS Points and Covariates and Exophthalmometer Readings at 1 Year

\begin{tabular}{|c|c|c|c|c|c|c|c|c|}
\hline & \multirow[b]{2}{*}{ Covariate } & \multirow{2}{*}{$\begin{array}{c}\text { No. patients } \\
\text { with covariate }\end{array}$} & \multicolumn{2}{|c|}{$\begin{array}{l}\text { No. patients } \\
\text { with CAS } \\
\text { points... }\end{array}$} & \multirow[b]{2}{*}{$P$} & \multicolumn{2}{|c|}{$\begin{array}{l}\text { No. patients with } \\
\text { exophthalmometer } \\
\text { reading of... }\end{array}$} & \multirow[b]{2}{*}{$P$} \\
\hline & & & $<2$ & $\geq 2$ & & $<2 \mathrm{~mm}$ & $\geq 2 \mathrm{~mm}$ & \\
\hline \multirow[t]{2}{*}{ Hyperthyroidism } & $\leq 2.5 \mathrm{mo}$ & 65 & 55 & 10 & 0.035 & 41 & 24 & 0.326 \\
\hline & $>2.5 \mathrm{mo}$ & 11 & 6 & 5 & & 5 & 6 & \\
\hline \multirow[t]{2}{*}{ Hypothyroidism } & $\leq 0.5 \mathrm{mo}$ & 61 & 50 & 11 & 0.478 & 35 & 26 & 0.378 \\
\hline & $>0.5 \mathrm{mo}$ & 15 & 11 & 4 & & 11 & 4 & \\
\hline \multirow[t]{2}{*}{ Smoking } & No & 68 & 56 & 12 & 0.188 & 43 & 25 & 0.252 \\
\hline & Yes & 8 & 5 & 3 & & 3 & 5 & \\
\hline \multirow[t]{2}{*}{ ATD } & No & 57 & 45 & 12 & 0.748 & 34 & 23 & 1.000 \\
\hline & Yes & 19 & 16 & 3 & & 12 & 7 & \\
\hline \multirow[t]{2}{*}{ TSI } & $\leq 1.8 \mathrm{mo}$ & 15 & 12 & 3 & 1.000 & 11 & 4 & 0.526 \\
\hline & $>1.8 \mathrm{mo}$ & 34 & 29 & 5 & & 21 & 13 & \\
\hline \multirow[t]{2}{*}{$\mathrm{FT}_{3}$} & $\leq 16.6 \mathrm{pmol} / \mathrm{L}$ & 31 & 27 & 4 & 0.320 & 21 & 10 & 0.598 \\
\hline & $>16.6 \mathrm{pmol} / \mathrm{L}$ & 28 & 21 & 7 & & 17 & 11 & \\
\hline
\end{tabular}


TABLE 6

QOL Data

\begin{tabular}{lccc}
\hline & \multicolumn{3}{c}{ QOL points } \\
\cline { 2 - 4 } Patients evaluated & Baseline & $1 \mathrm{y}$ & $P$ \\
\hline All patients & & & \\
Total & 113 & 75 & 0.673 \\
Mean & 1.51 & 1.05 & \\
SD & 2.32 & 1.59 & \\
No. patients with $\geq 2$ QOL points & 27 & 22 & \\
Total & 105 & 69 & \\
Mean & 3.90 & 3.14 & \\
SD & 2.24 & 1.46 &
\end{tabular}

*Only 75 patients completed QOL questionnaire; other patient excluded.

\section{Note on a Patient}

The youngest patient entering the study, a 10.6-y-old girl, had pain with eye movements, widened palpebral fissures, and diplopia in peripheral fields at the outset. Within a few weeks she experienced conjunctival redness and a sense of intermittent diplopia; the concerned physician prescribed a course of prednisone over 6 wk. Her symptoms, including the peripheral-field diplopia, subsided. At the end the year, increased proptosis appeared; with this manifestation and conjunctival redness, her CAS was then 2 . This young girl was the only patient to receive special therapy directed at the orbits.

\section{DISCUSSION}

\section{Overall Eye Changes}

The major goal of this investigation was to determine the appearance and disappearance of manifestations of GO and, where possible, the magnitude of any changes in 76 patients over the year after radioiodine therapy. Our CAS evaluations were based on a previously published objective method in which reproducibility of individual categories of measurement ranged between $77 \%$ and $100 \%$, with a mean of $88 \%$ for all categories (13). In 9 of the 10 CAS items, the net changes at $1 \mathrm{y}$ in number of patients afflicted ranged from -5 to +3 . No patient lost vision. Exophthalmometer readings constituted the only CAS item in which

TABLE 7

QOL Interaction with CAS Points and Exophthalmometer Readings: Number of Patients at 1 Year

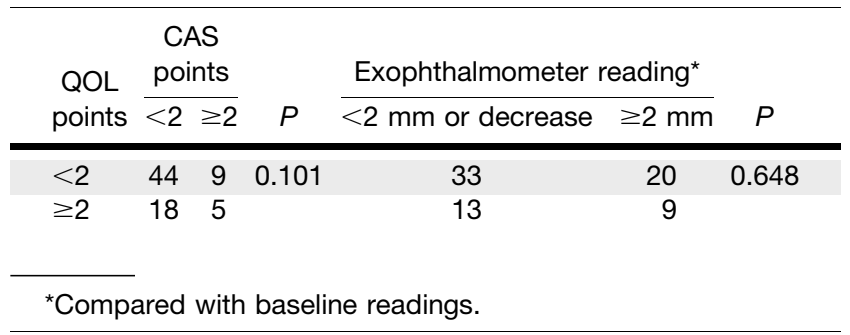

the number of patients involved at $1 \mathrm{y}$ was substantially increased. Much of the increases in exophthalmometer readings and in the increment of patients with exophthalmos occurred after 2 mo, but the trend from 2 mo to $1 \mathrm{y}$ was not significant. Moreover, the mean CAS, derived from all 10 items, did not significantly change between 2 mo and $1 \mathrm{y}$. Yet the number of patients with increased exophthalmometer readings deserves further analysis.

At $1 \mathrm{y}$, patients could be divided into 3 groups: those patients with exophthalmometer readings that were increased, those with readings that were decreased, and those whose readings remained unchanged; however, the mean readings of the 3 groups did not differ significantly at baseline. Therefore, there was no clinical clue to predict subsequent increases in readings. The magnitudes of changes were relatively modest; in those with increases, mean increments were 2.6 and $2.5 \mathrm{~mm}$, respectively, for right and left eyes and were not of clinical concern.

The search for new manifestations of GO was confounded by appearances and disappearances in the expressions of each CAS item throughout the year, and many of the changes may be unrelated to GO. Except for the youngest patient (described earlier), no other patient required additional therapy directed at the eyes.

\section{Reports in the Literature}

Other investigations of changes in GO $(1-4,6)$ have generally used clinical activity scores that evaluated the features included in the CAS; these were grouped into 4 objective categories: soft-tissue swelling and redness, extraocular muscle dysfunction manifested as diplopia, proptosis, and visual acuity by reading letters on charts. Thus, results described from different investigations appear to be based on comparable objective data.

Three publications reported increases in the manifestations of Graves' eye disease after radioiodine treatment of hyperthyroidism in Sweden (1), Italy (2), and Hong Kong (3). The number of patients with new or worse ophthalmopathy was significantly greater in patients treated with radioiodine than in patients managed by subtotal thyroidectomy (1), methimazole (1-3), and radioiodine accompanied by prednisone (2). Rates of increased ophthalmopathy after radioiodine therapy alone were $33 \%$ (1), 24\% (3), and 5\% (2); a few patients in each study received high doses of steroids or radiation therapy to counteract the increase in features of GO. The only patient in whom impaired vision developed was found among the 114 patients treated in Hong Kong (3).

In contrast, 72 patients in the United Kingdom showed a mean improvement in the 4 objective categories of a CAS (noted earlier) after therapy with ${ }^{131} \mathrm{I}$ (6). In Brazil, 22 patients treated with radioiodine showed no adverse effects in the eyes, and in fact, lid edema and lid retraction were reduced (4).

In previous reports, radioiodine therapy was followed by greater increases in mean ocular protrusion of $3.8 \mathrm{~mm}(1)$ and of $2 \mathrm{~mm} \mathrm{(2),} \mathrm{but} \mathrm{in} \mathrm{other} \mathrm{studies,} \mathrm{the} \mathrm{prominence} \mathrm{of} \mathrm{the}$ 
eyes was slightly decreased (6) or unchanged when measured by Hertel exophthalmometer and CT (4).

In our patients in whom exophthalmometer readings increased, this manifestation developed in about $40 \%$ during the final 6 mo of observation. This pattern is similar to the mean time of 6.7 mo for appearance of ocular features (3), whereas in another observation new or increased indications of GO appeared entirely within the first 6 mo (2). The difference in patterns is unexplained.

In our patients, increased exophthalmometer readings appeared more often in patients with normal measurements at the outset than in those with exophthalmos at baseline. Three studies have noted that new or increased manifestations in GO occurred predominately in patients who had preexisting ophthalmopathy $(1,2,10)$. On the other hand, previously unaffected patients experienced more eye disease in another report (3).

In 1 other publication, ophthalmopathy was temporary in $65 \%$ of patients in whom it was newly observed (2); all of these patients had received radioiodine therapy. It is possible that variations in $\mathrm{GO}$ occur unrelated to radioiodine treatment, and 1 or more covariates play a catalyst role (see later in this article). In any case, manifestations of GO, including diplopia and exophthalmos, may disappear without specific therapy.

\section{Associations with Covariates}

A significant correlation exists between a CAS of at least 2 points recorded at $1 \mathrm{y}$ and hyperthyroidism prolonged by at least 2.5 mo after radioiodine treatment. Tallstedt et al. (1) also recorded that prolonged hyperthyroidism, defined as requiring more than 1 treatment with radioiodine, was associated with eye changes. Only 2 of our patients required a second treatment with radioiodine, but early resolution of hyperthyroidism may have preventive effects for GO.

In some studies, smoking by patients was prevalent and may have played a role in the development of ophthalmopathy. Two investigations reporting increases in orbital disease were performed in Europe, where smoking, an activity well recognized to be associated with GO (18), was prevalent in $56 \%$ (1) and $55 \%$ (2) of the patients. In the study of Chinese patients, no relationship between the development of ophthalmopathy and smoking was found, but only $8 \%$ of those patients studied were smokers (3). In the United Kingdom, eye manifestations improved slightly after radioiodine, yet $67 \%$ of the patients were smokers $(6)$. Of the general populations within the United States, 10.5\%-27.6\% of patients have been identified as smokers (19); $8(10.5 \%)$ of the patients in our study were smokers, a prevalence consistent with the national average. We found no relationship between smoking and CAS points. However, the number of patients may have been too few for accurate analysis. Despite absence of statistical associations, smoking should still be considered a hazard to, among other diseases, GO.

All of the patients in each of 4 reports $(1,2,4,6)$ received treatment with an ATD before receiving radioiodine; it is possible, but cannot be determined from publications, that ATD therapy was associated with more or less GO. Kung et al. (3) found that levels of TSH receptor antibodies were significantly lower at the time of radioiodine treatment in patients whose eye disease became active. Tallstedt et al. (1) determined that in patients whose serum baseline $T_{3}$ levels exceeded twice the upper limit of the normal range, significantly more ophthalmopathy developed. In a retrospective evaluation (20) and a prospective study (3), prolonged hypothyroidism was significantly associated with progressive ocular changes; these reports led to preventive or prompt treatment of hypothyroidism by others $(2,4,6)$.

In our patients, a CAS of 2 or more points was not associated with covariates other than prolonged hyperthyroidism. No statistically significant relationship was found among prolonged hypothyroidism by more than $0.5 \mathrm{mo}$, ATD administration before radioiodine therapy, TSI levels, and $\mathrm{FT}_{3}$ concentrations of $16.6 \mathrm{pmol} / \mathrm{L}$ or more.

Increased exophthalmometer readings at $1 \mathrm{y}$ were not significantly associated with any of the covariates. Although the increased readings contributed substantially to the CAS, the statistical association of a CAS of 2 of more points with prolonged hyperthyroidism must have depended on contributions of other items in the scoring.

\section{QOL}

Because patients' appreciation of their ocular status is also important, we added results from a QOL questionnaire. Our study began before publication of GO-QOL, a questionnaire directed at patients with GO (21). Our questionnaire contains the 2 major categories of GO-QOL: appearance and vision. We added a question on eye pain. There was an insignificant decrease in the number of patients with 2 or more QOL points from baseline to $1 \mathrm{y}$. At $1 \mathrm{y}$, there was no statistically significant interaction between the patients with at least 2 QOL points and the number with at least $2 \mathrm{CAS}$ points or with the number of patients with increases in exophthalmometer readings at $1 \mathrm{y}$. Overall, the patients did not perceive an increase in ocular symptoms.

\section{Perspective}

This study was designed to evaluate the appearance and course of indices of GO in American patients who received radioiodine. Without an available control group of patients, the effects of treatment with ATDs or with surgical thyroidectomy cannot be addressed. Nevertheless, because the ophthalmopathy changes overall were variable, and the increases in exophthalmometer readings observed in some patients were modest, fears of complications from radioiodine therapy can be allayed.

A theoretic limitation of this study is the nonconsecutive patient entry. As stated before, there is no reason to believe either that patients declining entry into or leaving the study had marked eye disease or that manifestations developed that made them inclined not to participate. Bias exists in all studies in which patients are asked to participate; those who 
agree to participate may differ from those who decline. We do not believe there was bias on the part of the investigators who offered our patients a chance to participate in a nonthreatening research study.

In patients treated with radioiodine, concomitant steroid therapy was followed by an absence of increase in manifestations of GO (2). Given the relatively few and modest adverse changes seen in our patients, the benefits of treatment with prednisone would likely be found in few patients, and treatment with steroids should be applied to selected patients with advanced GO. From our results, the risks in treating all patients with prednisone are not warranted.

\section{CONCLUSION}

In evaluations of GO, CAS assessment found overall manifestations in fewer patients at $1 \mathrm{y}$ after radioiodine therapy; however, a modest increase in exophthalmometer readings was seen in 39\% of patients. Manifestations of CAS items frequently appeared and disappeared during the year after radioiodine therapy. Because increases in CAS points were correlated with prolonged hyperthyroidism, early termination of thyroid overactivity may be beneficial. Ocular symptoms were insignificantly fewer 1 y after radioiodine therapy. The observed changes do not warrant prophylactic treatment of patients with steroids.

\section{APPENDIX}

QOL Questionnaire for Patients with Graves' Eye Disease

\begin{tabular}{|c|c|c|c|c|}
\hline \multirow[b]{2}{*}{ Question } & \multicolumn{4}{|c|}{$\begin{array}{l}\text { Amount of pain and appearance } \\
\text { of eyes (rated on a scale of } 0-3 \text { ) }\end{array}$} \\
\hline & $\begin{array}{l}\text { None } \\
(0)\end{array}$ & $\begin{array}{l}\text { Mild } \\
(1)\end{array}$ & $\begin{array}{l}\text { Moderate } \\
\text { (2) }\end{array}$ & $\begin{array}{l}\text { Severe } \\
\text { (3) }\end{array}$ \\
\hline \multicolumn{5}{|l|}{$\begin{array}{l}\text { 1. How much } \\
\text { pain (including } \\
\text { burning) have } \\
\text { you had in } \\
\text { your eyes in } \\
\text { the past week? }\end{array}$} \\
\hline \multirow{2}{*}{$\begin{array}{l}\text { If you have } \\
\text { had pain, in } \\
\text { which eye(s) } \\
\text { was the pain?* }\end{array}$} & $\begin{array}{l}\text { right } \_ \text {; } \\
\text { left } \_; \\
\text {both } \_\end{array}$ & $\begin{array}{l}\text { right } \_ \text {; } \\
\text { left } \_; \\
\text {both } \_\end{array}$ & $\begin{array}{l}\text { right } \_ \text {; } \\
\text { left } \_; \\
\text {both } \_\end{array}$ & $\begin{array}{l}\text { right } \_ \text {; } \\
\text { left } \_; \\
\text {both } \_\end{array}$ \\
\hline & Normal (0) & $\begin{array}{c}\text { Mildly } \\
\text { abnormal (1) }\end{array}$ & $\begin{array}{l}\text { Moderately } \\
\text { abnormal (2) }\end{array}$ & $\begin{array}{l}\text { Severely } \\
\text { abnormal (3) }\end{array}$ \\
\hline \multicolumn{5}{|l|}{$\begin{array}{l}\text { 2. Rate the } \\
\text { appearance } \\
\text { of your eyes } \\
\text { as seen in a } \\
\text { mirror (swelling, } \\
\text { eyelid changes, } \\
\text { etc.). } \\
\text { 3. Rate your } \\
\text { ability to see } \\
\text { using glasses } \\
\text { as prescribed: } \\
\text { a. near sight } \\
\text { (reading) } \\
\text { b. distance } \\
\text { sight (driving car) }\end{array}$} \\
\hline
\end{tabular}

\section{ACKNOWLEDGMENTS}

The authors are indebted to Barbara Michael for diligent aid in obtaining ophthalmologic and QOL data and Susan Lawson for shepherding patients for appointments. Also a great deal of help came from Drs. Barry Shulkin, Anca Avram, and Nazanene Esfandiari, who recruited patients. Drs. Harjeet Kaur and Wayne T. Cornblath evaluated the eyes in some patients. Suzanne Murphy provided valuable assistance in constructing tables for the manuscript. This research was supported by the General Clinical Research Center at the University of Michigan through a grant from the National Institutes of Health (NIH MO1-RR00042).

\section{REFERENCES}

1. Tallstedt L, Lundall G, Torring O, et al. Occurrence of ophthalmopathy after treatment for Graves' hyperthyroidism. N Engl J Med. 1992;326:1733-1738.

2. Bartalena L, Marcocci C, Bogazzi F, et al. Relation between therapy for hyperthyroidism and the course of Graves' ophthalmopathy. N Engl J Med. 1998;338: 73-78.

3. Kung AWC, Yau CC, Cheng A. The incidence of ophthalmopathy after radioiodine therapy for Graves' disease: prognostic factors and the role of methimazole. J Clin Endocrinol Metab. 1994;79:542-546.

4. Manso PG, Furlanetto RP, Wolosker AMB, Paiva ER, de Abreu MT, Maciel RMB. Prospective and controlled study of ophthalmopathy after radioiodine therapy for Graves' hyperthyroidism. Thyroid. 1998;8:49-52.

5. Bonnema SJ, Bartalena L, Toft AD, Hegedis L. Controversies in radioiodine therapy: relation to ophthalmopathy, the possible radioprotective effect of antithyroid drugs, and use in large goiters. Eur J Endocrinol. 2002;147:1-11.

6. Perros P, Kendall-Taylor P, Neoh C, Frewin S, Dickinson J. A prospective study of the effects of radioiodine therapy for hyperthyroidism in patients with minimally active Graves' ophthalmopathy. J Clin Endocrinol Metab. 2005;90:5321-5323.

7. Hamilton RD, Mayberry WE, McConahey WM, Hanson KC. Ophthalmopathy of Graves' disease, a comparison between patients treated surgically and patients treated with radioiodide. Mayo Clin Proc. 1967;42:812-818.

8. Barbosa J, Wong E, Doe RP. Ophthalmopathy of Graves' disease. Arch Intern Med. 1972;130:111-113.

9. Gwinup G, Elias AN, Ascher MS. Effect on exophthalmos of various methods of treatment of Graves' disease. JAMA. 1982;247:2135-2138.

10. Sridama V, DeGroot LJ. Treatment of Graves' disease and the course of ophthalmopathy. Am J Med. 1989;87:70-73.

11. Solomon B, Glinoer D, Lagasse R, Wartofsky L. Current trends in the management of Graves' disease. J Clin Endocrinol Metab. 1990;70:1518-1524.

12. Alexander EK, Larsen PR. High dose ${ }^{131} \mathrm{I}$ therapy of the treatment of hyperthyroidism caused by Graves' disease. J Clin Endocrinol Metab. 2002;87:10731077.

13. Mourits MPh, Prummel MF, Wiersinga WM, Koornneef L. Clincial activity score as a guide in the management of patients with Graves' ophthalmopathy. Clin Endocrinol (Oxf). 1997;47:9-14.

14. Frueh BR. Graves' eye disease: orbital compliance and other physical measurements. Trans Am Ophthalmol Soc. 1984;82:492-598.

15. Frueh BR, Musch DC, Garber FW. Exophthalmometer readings in patients with Graves' eye disease. Ophthalmic Surg. 1986;17:37-40.

16. Migliori ME, Gladstone GJ. Determination of the normal range of exophthalmetric values for black and white adults. Am J Ophthalmol. 1984;98:438-442.

17. Tsai CC, Kau HC, Kao SC, Hsu WM. Exophthalmos of patients with Graves' disease in Chinese of Taiwan. Eye. 2006;20:569-573.

18. Vestergaard P. Smoking and thyroid disorders: a meta-analysis. Eur J Endocrinol. 2002;146:153-161.

19. Centers for Disease Control and Prevention. State-specific prevalence of cigarette smoking and quitting among adults: United States, 2004. Morb Mortal Wkly Rep. 2005;54:1124-1127.

20. Tallstedt L, Lundell G, Blomgren H, Bring J. Does early administration of thyroxine reduce the development of Graves' ophthalmopathy after radioiodine treatment? Eur J Endocrinol. 1994;130:494-497.

21. Terwee CB, Gerding MN, Dekker FW, Prummel MF, van der Pol JP, Wiersinga WM. Test-retest reliability of the GO-QOL: a disease-specific quality of life questionnaire for patients with Graves' ophthalmopathy. J Clin Epidemiol. 1999;52875-884. 